\title{
Linking global consumer culture and ethnocentric consumerism to global citizenship: exploring the mediating effect of cultural intelligence
}

\author{
Aluisius Hery Pratono \\ Faculty of Business and Economics, Universitas Surabaya, Surabaya, Indonesia, and \\ Denni Arli \\ Labovitz School of Business and Economics, University of Minnesota Duluth, Duluth, \\ Minnesota, USA
}

\begin{abstract}
Purpose - This article attempts to understand the impact of global consumer culture and ethnocentric consumerism on global citizenship by identifying the mediating effect of cultural intelligence.

Design/methodology/approach - The proposed structural equation model explains the relationship between global consumer culture, ethnocentric consumerism, and global citizenship. The empirical analysis involves an online survey targeted young people in Indonesia context.

Findings - The empirical evidence broadly supports the view that cultural intelligence strengthens the impact of global consumer culture and ethnocentric consumerism on global citizenship. There is a strong tendency in this study to suggest that global consumerism will not be able to contribute to global citizenship unless cultural intelligence provides as a mediating variable. However, the results do not support the mainstream literature, which suggests that ethnocentric consumerism harms global citizenship.

Originality/value - This study extends the discussion on achieving sustainable development by examining global citizenship leads to a better understanding of consumer culture theory.
\end{abstract}

Keywords Global consumer culture, Global citizenship, Cultural intelligence, Ethnocentric consumerism

Paper type Research paper

\section{Introduction}

The conventional wisdom of globalisation states that international trade helps countries to enhance their income-generating capacity, which becomes an essential prerequisite for achieving sustainable development (United Nations, 2015). Global citizenship (GC) provides an opportunity for sustainable development by allowing individuals to get involved in global civic engagement (Goodier et al., 2018). GC education becomes the main framework for the implementation of the fourth sustainable development goal by ensuring "inclusive and equitable quality education and lifelong learning for all" (UNESCO, 2015).Integrating sustainable development into the academic-community partnership is an ethical responsibility to promote global citizens (Upvall and Luzincourt, 2019).

The concept of GC argues that everyone on Earth needs to develop a worldwide network to vow the value to meet their specific condition as humans (Lianaki-Dedouli and Plouin, 2017). The activities of GC attempt to promote global awareness, cultural diversity, social justice and environmental sustainability (Reysen and Hackett, 2017). The private sector needs to support the initiative for the sustainable development goal through behavioural

This research gains financial support from the Ministry of Research and Higher Education (RISTEKBRIN) the Government of Indonesia.

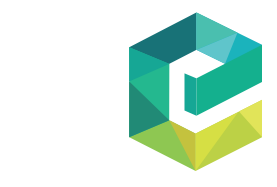

International Journal of Sociology and Social Policy (c) Emerald Publishing Limited DOI 10.1108/IJSSP-10-2019-0212 
changes of individuals and organisations, which become a prerequisite for sustainable development (Dobson, 2007; Hahn, 2009). Hence, international business research calls for further discussion to develop the concept of both positive and negative dispositions towards globalisation (Bartsch, Piefler and Diamantopoulos, 2016).Previous studies still concern on $\mathrm{GC}$ in developed countries and call for further exploration in emerging countries (Scott and Cnaan, 2020).

The ethnocentric consumerism (EC) seems to become a counterpart of global consumer culture (GCC), which raises a series of paradoxes that spring from the crisis of neoliberal politics (Lekakis, 2015).Primary literature suggests that ethnocentric consumers support the protectionism and reject the globalisation by avoiding foreign products and service (Sharma et al., 1995; Okazaki et al., 2010; Feurer et al., 2016). On the contrary, some consumers face conflicting emotion whether to support the national economy by purchasing domestic products or discourage to buy the local products due to quality or price that does not meet their expectation (Siagmaka and Balabanis, 2015). Baruk (2019) argues that EC comes to various level, which one of them, hence, the empirical study is required to provide a solid foundation to understand the global consumer behaviour towards GC (Goodier et al., 2018).

The article aims to understand the nature of global and consumer culture by examining the role of cultural intelligence (CQ) in the relationship between GCC, EC, and GC. The second section of this article involves a literature review with the proposed hypothesis, followed by research method where we provide how we collect data and conduct the analysis. This study provides empirical evidence, which involves a proposed model and sample data from an online survey. The last section concerns the theoretical and managerial implication derived from the literature and empirical results.

\section{Literature review}

\subsection{Enabling global citizenship for sustainable development}

Global citizenship refers to a belief that everyone belongs to multiple, diverse, local and nonlocal networks, which allows him or her to seek further recognition and respect for human rights for all citizens of the world (Brown, 2016). The idea of world citizenship has been emerging among those who believe in world governance since the early 1950s. In contrast, the term GC becomes popular among individual activists for global causes (Carter, 2013). Hence, the concept of GC becomes popular following the Universal Declaration of Human Rights, the Sustainable Development Goals and the Paris Agreement in 2015 (UN Chronicle, 2018). Education for GC attempts to promote a healthy institution and equitable society by encouraging citizens to refine the biosphere, altruistic, and egoistic components of their values (Wynveen et al., 2012).The concept of GC has been emerging into the extensive human framework to affirm the belief toward the specifics of their condition as humans (LianakiDedouli and Plouin, 2017). The global civic engagement dimension also adopts a more local way, such as volunteering with local communities (Goodier et al., 2018).

Consumer culture refers to central shared values of culture, which have to do with consumption (Goodman and Cohen, 2004). Community participation is essential to address a lack of public service availability but provides a conflict of interest from different cultural backgrounds (Pratono and Maharani, 2018). Consumer culture refers to a social arrangement that involves the intersection between the cultural experience and social resources, between ways of life and the symbolic material sources under a market mechanism (Sheth and Maholtra, 2009). Consumer cultural theorist observes the consumption contexts to generate new constructs to extend the consumer research by exploring the way of individual consumers enacting and personalising cultural script (Arnould and Thompson, 2005). The consumer culture theory attempts to understand the consumption patterns at the various social and cultural context (Cook and Ryan, 2015). The information technology encourages interactions between the consumers beyond geographical boundaries to offer global citizen to 
interact, approach, support, oppose and criticise social, cultural and business institutions with a proactive voice (Dey et al., 2020).

\subsection{Global consumer culture and ethnocentric consumerism}

GCC becomes prominence with the proliferation of cultural difference in the globalisation context (Arnould, 2010). GCC requires the capability to deal with global cultural integration by adapting the different cultural background (Earley et al., 2006), which provides opportunities to develop the consumer decision-making model based on global citizen paradigm (Laroche, 2016). The GCC demonstrates how consumers become the membership of global consumers by purchasing the products with a worldwide cultural symbol (Okazaki et al., 2010). This phenomenon involves CQ, which propounds an ideal framework for promoting intercultural competence GC (Goh, 2012). Social activities with global awareness, cultural diversity, social justice- and environmental sustainability are associated with the main activities of GC (Reysen and Hackett, 2017). The advent of digital technology has encouraged the changing of consumer interaction with a more complex orientation by embracing the lived convenience and experience through sharing information (Dey et al., 2020).

The concept of EC springs from the inferiority perception from other groups (Siagmaka and Balabanis, 2015). EC is a unique consumption behaviour that adopts the economic motives for in-group bias (Zeugner-Roth et al., 2015). Some people fear that import threatens the domestic industry and reduce job creation (Lekakis, 2015). However, there are fears about the GCC from local brands, which are positioned as explicit competitors (Arnould, 2010), while many people are still at an ethnocentric level of development (McCrindle, 2010). A niche product from the local industry may attract favourable local consumer attitudes, which concern to promote ethnically produced products with positive stakeholder relations (Tseng et al., 2018). The ethnocentrism is essential for consumer attitudes through blame attributions (Barbarossa et al., 2018).

$\mathrm{CQ}$ behaviour refers to the act in specific ways to deal with various cultures (Earley et al., 2006). CQ demonstrates the capability to deal with cultural diversity, which has relevance to an individual, group, organisation and even nation (Ang and Van Dyne, 2015). People in more multi-ethnic societies are more likely to experience intercultural contact compare to people in more ethnically homogenous one (Bernardo and Presbitero, 2017). CQ is different from other intelligence, such as intelligence quotient (IQ) and emotional intelligence (EQ). CQ focuses on setting and interactions characterised by cultural diversity. Generally, non-verbal behaviour demonstrates the signals produced or encoded, instead of the process of attributing meaning (Knapp et al., 2014). Nonverbal facets pervade virtually every communication act, which can lead to both misunderstanding and understanding (Burgoon et al., 2016).

As corporations attempt to adopt the sustainable development principle, the initiative to gain customers' support needs to deal with various global challenges, including ethnic rivalries, community economic dependency and unpredictable violence (Boutilier, 2017). The cultural information becomes crucial in both conception and application, which requires sensitivity to various stakeholders regarding their languages, knowledge, religion and identity (Giorgi et al., 2017). CQ arises in the economy of various industries. In the tourism industry, CQ allows the business players to explore multiple places where the different culture of consumers, employees, suppliers and other people come into contact (Feurer et al., 2016). The IT industry shows that social networks enhance the development of CQ (Hu et al., 2018).

\subsection{Hypothesis development}

GCC is a critical element to devote the resources for the worldwide agenda (Giorgi et al., 2017). The GCC encourages young consumers to become the global consumers by purchasing the

\section{Mediating effect of cultural intelligence}

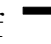


products with a given global culture symbol (Okazaki et al., 2010), which implies on developing the multi-cultural identities (Stizhakova et al., 2008). The concept of consumer culture covers not only the consumption of material products but also identities and lived experiences of consumption, which involves the interaction between consumers and brands, companies and market institutions (Dey et al., 2020).

Appreciation of other cultures is the main component of GC (Lyons et al., 2012), which moves beyond talk to demonstrate that they can engage in purposeful global civic actions (Cushner, 2015). GC illustrates how an individual embraces the self through the market under the guise of universal consciousness (Lyons et al., 2012). The process of GC involves multilayered ways, which perform through international volunteering (Smith et al., 2013). Universal cultural symbol creates a value in which a person respects participation in the global networks (Stizhakova et al., 2008). GCC shapes charitable behaviour to generate selfsatisfaction, to avoid guilt and to create congruence (Laroche and Teng, 2019).

\section{H1. GCC has a positive effect on GC.}

The globalisation has brought cultural integration into a business environment, which can lead the citizens to experience a deep-rooted class prejudice (Cleveland et al., 2016). It is essential to develop the capability to bridge diverse internalised cultures (Korzilius et al., 2017). Individuals adopt global citizen behaviour by developing their capacity to admire shared across borders and cultures. (Lianaki-Dedouli and Plouin, 2017).The understanding of culture expresses the acceptability to the different culture, which in turn improves the ability to build social capital in the cross-cultural context. CQ prevails in global citizen adjustment through allocation the effort and energy in the cross-cultural setting that actors attempt to adjust (Huff et al., 2014). Personality and exposure to different cultures are related to individual differences in CQ through the interconnected culture (Bernardo and Presbitero, 2017).

CQ promotes cross-cultural to enhance individual task performance for international organisations (Presbitero and Toledano, 2017). A global mindset is relevant where CQ becomes a sufficient intercultural competency for individuals who work at international organisations (Andresen and Bergdolt, 2017). CQ concerns the cultural norms and practices with appropriate emotional expression and awareness of culturally different to develop a GC mindset (Sharma et al., 1995).Engagement at volunteering activities within different communities does not only enhance the ability to live, work and engage on a global level but also develop more a distinctive identity as a world citizen (Scott and Cnaan, 2020).

H2. GCC has a positive impact on CQ.

Ethnocentric consumers tend to reject GC with a given global culture symbol (Okazaki et al., 2010). There is a negative effect of EC towards a willingness to buy foreign products (Sharma et al., 1995). Hence, ethnocentric consumers support the protectionism implemented by the government and the consumers (Feurer et al., 2016). However, consumers simultaneously identify the products and services with a national identity may have inconsistency on the order of proposed antecedents towards GC (Bartsch et al., 2016).Consumers with levels of ethnocentrism demonstrate a more considerable amount of activation in brain regions related to distrust when processing a global brand (Casado-Aranda et al., 2020).

The appreciation of local products does not necessarily imply that they discriminate against foreign products (Zeugner-Roth et al., 2015). Ethnocentric youths may welcome GC by considering that the global brand provides a pathway of success for their communities (Banna et al., 2018). Firms may expand from the home-based industry and begin to operate in many other countries, but they tend to be ethnocentric in the name of national interest. Pursuing local procurement does not mean they go in partnership with locals (Lehmberg et al., 2013). For the perspective of young millennial customers, the mono-ethnic-targeted 
message seems to be ineffective to influence the multi-cultural identities of young people. At the same time, global communication becomes more useful in marketing strategies for the ethnically diverse millennial (Laroche and Teng, 2019).

H3. EC has a negative impact on GC.

The EC demonstrates the phenomenon of consumer preference for prejudice against imported products, which can be a cultural bias against GC (Wang, 2004). The ethnocentric campaigns attempt to protect local jobs, improve trade balances and defend national identities by rejecting the argument about globalisation. (Siagmaka and Balabanis, 2015). Previous studies suggest that the relationship between EC and CQ tends to be negative (Trede et al., 2013; Pekerti and Arli, 2017). The individual with high EC becomes less CQ (Young et al., 2017). CQ may do not work at convenience products but merely at products with high economic costs (Balabanis and Siamgka, 2017). The effects of EC seem not to be uniform across products. Ethnocentric advertising to promote local brand may harm foreign brands (Han and Guo, 2018).

Individual consumers could be cultural intelligent and ethnocentric. Consumers with high $\mathrm{CQ}$ tend to show an interest in ethnicity than ethnocentric. In contrast, consumers with low CQ are not excited in the group and are not interested to learn from a different culture (Barnes, 2015). Individuals with strong cultural intelligent and ethnocentric value attempt to learn different cultures but the concern with their cultural identities or feeling opposite toward other cultures (Young et al., 2017).Baruk (2019) indicates that there are various levels of EC, which provide different impact on willingness to avoid the global brand. One type of consumers who attempt to accept global brand includes those who become potential ethnocentric consumers. This type of consumer concerns only local products and advertisements for behavioural reasons (Baruk, 2019).

\section{H4. EC has a negative impact on CQ.}

CQ promotes global citizen, which becomes essential for the development of any globalised nation (Sharma et al., 1995). Consumers with high CQ understand the challenges of cross-culture by enhancing the capability to engage in adjustment behaviours (Ismail and Nisar, 2015). Understanding other cultures provide a long-term solution to the world's problems outlined in the UN Sustainable Development Goal (Giorgi et al., 2017). Strong CQ background provides support to promote GC, including appropriate environmental behaviour on daily (Buket and Oktay, 2018), which in turn force social exchange relationships to lead prosocial behaviour by triggering moral obligation (Kim and Qu, 2020).

The theory of multiple intelligences underpins CQ, which shows how the cross-cultural aspect of knowledge supports adaptive cultural adjustment (Sharma and Hussain, 2017). The $\mathrm{EC}$ on branded products from developed countries may demonstrate mixed impact (Wang, 2004). CQ is more subject to change from a short-term intervention from transforming the EC to GC (Young et al., 2017). Along with cross-cultural experience, the capability to adapt to a different culture develops a global citizen with cosmopolitan identity (Lyons et al., 2012). The role of intelligence on GC involves the elaboration of social skills such as listening, inspiring and building relationships, which in turn develop voluntary behaviours in a global context (Mekpor and Dartey-Baah, 2020).

H5. CQ behaviour has a positive impact on GC.

\section{Research method}

\subsection{Research design}

This study uses a quantitative research design to address the question of whether the GCC influences GCs. The quantitative approach focus on objectivity is what enables the
Mediating effect of cultural intelligence

\section{$\longrightarrow$}


researchers to generalise the findings of a research study beyond the particular situation involved in that study. The quantitative approach defines the variables from the previous literature and links them together to frame hypotheses before data collection (Brannen, 2016). Adapted from the literature, the model involves a mediating variable of CQ to explain the complicated relationship.

The studying behaviour uses the form of measurement, which should reflect the nature of the problem and the posed questions (Martin and Beteson, 2004). The emerging information technology allows online surveys to replace the paper or telephone survey, which also is increasingly common in health research. The rationale behind the online survey embraces the accessibility to meet the expected high response rates. In contrast, the online responses generate challenges for private information and rationale for nonparticipation (Annear, 2018).

\subsection{Data collection}

This study conducted an online survey at the individual consumer level with a clusterrandomised sample approach and additional snowball sampling. The clustering approach concerns on five cities in Indonesia, which reflect the varied geography and demographic structure. As communicative techniques and application are considered as essential to increase response rates (Fan and Yan, 2010), the researchers sent an email to each respondent and asked them to fill out the questionnaires within Indonesia translation.

The survey used Google forms to make sure that the respondents easily find the survey Website and delightfully open the questionnaires, which was conducted in Indonesia between August and December 2017. The survey targeted the participants who regularly accessed social media by sending the survey invitation via various communicative techniques, i.e. Instagram, Facebook, Lines and Messenger. The surveyors also asked the respondents to forward the invitation email to their colleagues who are qualified and interested in participation. The additional snowballing approach enhances the accessibility of potential respondents (Annear, 2018).

After data screening, there are 611 data from the respondents with ages between 15 and 24 years. Among them, $55 \%$ of representing college students, $42 \%$ were high school students, and the rest respondents stated as employees. Among those, $62 \%$ of respondents stayed in Surabaya and $34 \%$ in Jakarta, while the rest lived in different cities.

\subsection{Measures}

The model has four constructs, i.e. GC, GCC, consumer ethnocentric and CQ. We adopt the measures of $\mathrm{GCC}, \mathrm{GC}, \mathrm{EC}$, and $\mathrm{CQ}$ behaviour from the previous literature: GCC from Cleveland et al. (2016), GC from Reysen and Hackett (2017) (Reysen and Hackett, 2017), EC from (Klein, 1999) and CQ from Ang and Van Dyne (2015) (Ang and Van Dyne, 2015). The measures used the seven-point Likert scale with the seven categories from (1) strongly disagree to (7) strongly agree (Annex 1 ).

To measure the GCC, we refer to the seminal work of Cleveland et al. (2016). Initially, there were seven measures. After the factor analysis, we used four items, which are relevant to the models. This study highlights international brands, famous people and a global brand, which represent the GCC. The items include "[I] identify with famous international brands", "I pay attention to the famous worn by people in my age group that live in other countries" and "Advertising by foreign or global brands has a strong influence on my clothing choices".

According to Reysen and Hackett (2017), GC consists of eight items. The factor analysis indicates four relevant statements: "the various cultures of this world interact socially", "my actions in my local environment may affect people in other countries", "stay informed of current issues that impact international relations" and "I am connected to people in other countries” (Reysen and Hackett, 2017). 
For measures of EC, we adapted from the work of Klein (1999), which indicates 16 items. After factor analysis, there were eight items remain reliable: "should buy [Indonesian-made] products", "purchase product manufactured in Indonesia", "[We should be very little trading or purchase goods from other countries", "Foreign products should be taxed heavily" and "Indonesian consumers who purchase products made in other countries are responsible for putting their fellow Indonesians out of work" (Klein and Ettensoe, 1999).The measures of CQ behaviour from the works of Ang and Van Dyne (2015) demonstrate that factor analysis confirms all five measures to become relevant to the latent variable of CQ behaviour. The items include "change verbal behaviour", "suit different cross-culture situations", "rate of speaking", "non-verbal behaviour" and "facial expression".

\subsection{Analysis}

The hypothesis test uses covariant-base structural equation model, which involves simultaneously analyse multiple variables with obtained measures from an online survey to collect primary data. The purpose of the regression analysis is then to test the hypothesis of the relationship between GC, EC and GCC by exploring whether $\mathrm{CQ}$ provides valuable for extending the model with mediating variable. The structural equation model determines how the proposed model estimates the covariance matrix for a sample data.

\section{Results}

Table 1 shows the descriptive statistics of the latent variables. All the observed variables are concerned at the medium level with various levels of the mean. GC is the lowest variables with an average rate of 3.96, while the highest level occurred at global cultural consumption and EC. CQ behaviour is more moderate level than the other variables with an average level of 4.08 , and the standard deviation is also the lowest if we compare to other variables (see Table 2).

Initially, there were seven items of GCC, four elements of EC, eight elements of GC and five items of CQ behaviour. The reliability assessment relies on Cronbach's alpha (CA). The results indicate that all coefficients of $\mathrm{CA}$ of the latent variables are higher than 0.70 , which suggest that the internal consistency of the standard range is quite high. The GC has 0.800 , which is the highest level of reliability values that are followed by EC with 0.784 and CQ with 0.782 of CA coefficients. GCC has the lowest level of reliability value with 0.737 (Table 3).

The Keiser-Meyer-Olkin (KMO) values indicate the degree of each variable in predicting without error by the other variables, which this study uses. The results show that the values

\begin{tabular}{lccccc}
\hline Latent variables & Mean & STD & CQ & GCC & GC \\
\hline Cognitive intelligence & 4.080 & 1.013 & $0.331^{*}$ & $0.281^{*}$ & $0.458^{*}$ \\
Ethnocentric consumerism & 4.853 & 1.130 & & $0.421^{*}$ & $0.385^{*}$ \\
Global citizenship & 3.963 & 1.121 & & & $0.311^{*}$ \\
Global consumer culture & 4.844 & 1.157 & & &
\end{tabular}

Note(s): *significant at alpha $5 \%$

Table 1.

Descriptive statistics and correlation

\begin{tabular}{lccrr}
\hline Latent variables & Cronbach's alpha & KMO & Bartlett's test & \\
\hline GCC & 0.737 & 0.733 & Significant & Table 2. \\
GC & 0.800 & 0.857 & Significant & Exploratory factor \\
EC & 0.784 & 0.764 & Significant & analysis \\
CQ & 0.782 & 0.827 & Significant & \\
\hline
\end{tabular}


are between 0.7 and 0.8 , which suggest that factor analysis is likely to be appropriate. The GC has the highest $\mathrm{KMO}$ value of 0.857 , which is followed by EC and CQ with 0.764 and 0.827 , respectively. The lowest level of KMO value occurs with GCC, which is 0.733 . Bartlett's test also confirms that the variances of each latent variable are equal, which are also consistent with the $\mathrm{CA}$ values.

Framework analysis begins with the proposed structural equation model and hence followed by revised with confirmatory factor analysis. The results indicate that Root Mean Square Error of Approximation (RMSEA) value is 0.071, which is less than 0.08 , that suggests an acceptable fit. However, the proposed model has Normed Fit Index (NFI) value 0.757, which means less satisfactory fit. The NFI test shows that the revised model has better goodness of fit. This result also similar to those of Tucker Lewis Index (TLI) test, which suggests that the proposed model has TLI less than 0.765, while the revised model has TLI value higher than 0.90. Akaike Information Criterion (AIC) values suggest that the revised model is better than the proposed model. Hence, this study uses the revised model (Table 4).

For EC, Table 5 shows that EC has a significant impact on GC. There is also a considerable impact of EC on CQ and CQ has a significant impact on GC. The coefficient of the direct effect of EC on GC (0.263) decreases in the presence of CQ. Table 5 shows the results of regression without a moderating variable, which indicates that $\mathrm{EC}$ has a significant impact on $\mathrm{GC}$. The

Table 3.

Goodness of fit

\begin{tabular}{lccc}
\hline Latent variables & Proposed & Revised & Criteria \\
\hline CMIN/DF & 5.558 & 2.817 & $<3$ \\
Root Mean Square Error of Approximation (RMSEA) & 0.071 & 0.045 & $<0.08$ \\
Normed Fit Index (NFI) & 0.757 & 0.946 & $>0.90$ \\
Tucker Lewis Index (TLI) & 0.765 & 0.949 & $>0.90$ \\
PNFI & 0.673 & 0.662 & Greater \\
Akaike Information Criterion (AIC) & 0.370 & 0.338 & Smaller \\
\hline
\end{tabular}

\begin{tabular}{|c|c|c|c|c|c|c|}
\hline \multicolumn{3}{|l|}{ Path analysis } & \multirow{2}{*}{$\begin{array}{c}\text { Estimate } \\
0.263\end{array}$} & \multirow{2}{*}{$\frac{\mathrm{S} . \mathrm{E}}{0.037}$} & \multirow{2}{*}{$\frac{\mathrm{C} . \mathrm{R}}{7.108}$} & \multirow{2}{*}{$\frac{P}{* * *}$} \\
\hline $\mathrm{CQ}$ & $\leftarrow$ & CE & & & & \\
\hline $\mathrm{CQ}$ & $\leftarrow$ & $\mathrm{GCC}$ & 0.172 & 0.049 & 3.490 & $* * *$ \\
\hline $\mathrm{GC}$ & $\leftarrow$ & $\mathrm{GCC}$ & -0.009 & 0.029 & -0.304 & 0.761 \\
\hline GC & $\leftarrow$ & CQ & 0.267 & 0.034 & 7.729 & $* * *$ \\
\hline GC & $\leftarrow$ & $\mathrm{EC}$ & 0.131 & 0.024 & 5.359 & $* * *$ \\
\hline $\mathrm{ECO4}$ & $\leftarrow$ & $\mathrm{EC}$ & 1.055 & 0.050 & 21.276 & $* * *$ \\
\hline EC03 & $\leftarrow$ & $\mathrm{EC}$ & 1.000 & & & \\
\hline EC02 & $\leftarrow$ & $\mathrm{EC}$ & 1.035 & 0.049 & 21.130 & $* * *$ \\
\hline $\mathrm{EC} 01$ & $\leftarrow$ & $\mathrm{EC}$ & 1.034 & 0.050 & 20.546 & $* * *$ \\
\hline CQ5 & $\leftarrow$ & CQ & 1.000 & & & \\
\hline CQ4 & $\leftarrow$ & $\mathrm{CQ}$ & 1.020 & 0.056 & 18.130 & $* * *$ \\
\hline CQ3 & $\leftarrow$ & $\mathrm{CQ}$ & 0.942 & 0.057 & 16.593 & $* * *$ \\
\hline CQ2 & $\leftarrow$ & $\mathrm{CQ}$ & 0.914 & 0.056 & 16.439 & $* * *$ \\
\hline CQ1 & $\leftarrow$ & $\mathrm{CQ}$ & 0.940 & 0.057 & 16.573 & $* * *$ \\
\hline GC1 & $\leftarrow$ & $\mathrm{GC}$ & 1.000 & & & \\
\hline GC5 & $\leftarrow$ & $\mathrm{GC}$ & 1.460 & 0.127 & 11.513 & $* * *$ \\
\hline GC6 & $\leftarrow$ & $\mathrm{GC}$ & 1.643 & 0.144 & 11.424 & $* * *$ \\
\hline $\mathrm{CC} 01$ & $\leftarrow$ & GCC & 1.000 & & & \\
\hline $\mathrm{CC} 02$ & $\leftarrow$ & GCC & 1.449 & 0.113 & 12.779 & $* * *$ \\
\hline $\mathrm{CC} 03$ & $\leftarrow$ & GCC & 1.213 & 0.089 & 13.678 & $* * *$ \\
\hline $\operatorname{Note}(\mathbf{s}): * * * \mathrm{~s}$ & it at & & & & & \\
\hline
\end{tabular}

Table 4.

Regression results

Note(s): ***significant at alpha $1 \%$ 
results suggest that direct, indirect and total effects are positive and significant. The overall effect of EC on GC is 0.201 , which come from the indirect effect of 0.070 and direct impact of 0.131. The results suggest that variation of 0.201 units difference in GC explains a unit difference in EC. Hence, the value of 0.070 shows the effect of EC, which turns into CQ. By rejecting the null hypothesis that the indirect effect is equal to zero, this study indicates that the indirect impact of EC on GC through a mediating effect of $\mathrm{CQ}$.

For GCC, Table 5 shows that GCC has a substantial impact on CQ and CQ has a significant effect on GC. However, GCC has no direct impact on GC. According to Baron and Kenny, there is nothing to mediate, as the direct effect is not significant (Baron and Kenny, 1986). The approach is debatable since the analysis is encouraged to move forward if there is an excellent theoretical background about the relationship (Shrout and Bolger, 2002). The regression without moderating variable shows that both GCC has a significant impact on $\mathrm{GC}(t=7.584$ and $p=0.00)$ and $(t=6.043$ and $p=0.00)$ (Table 6). Hence, if GCC has no considerable effect on GC, CQ provides the full mediating effect on the relationship between GCC and GC.

\begin{tabular}{lcccc}
\hline Path & Coefficient & Std Deviation & $T$ statistics & $P$-value \\
\hline GCC - > GC & 0.414 & 0.055 & 7.584 & 0.000 \\
EC - > GC & 0.335 & 0.055 & 6.043 & 0.000
\end{tabular}

Mediating effect of cultural intelligence

\begin{tabular}{|c|c|c|c|c|c|c|}
\hline Path & Original Sample (O) & Sample Mean (M) & Std. Dev (STDEV) & $T$ Statistics & $P$ Values & \\
\hline $\mathrm{EC}->\mathrm{GC}$ & 0.237 & 0.249 & 0.061 & 3.862 & 0.000 & \\
\hline $\mathrm{EC}->\mathrm{CQ}$ & 0.182 & 0.185 & 0.066 & 2.756 & 0.006 & \\
\hline GCC- $>$ GC & 0.305 & 0.307 & 0.062 & 4.892 & 0.000 & Table 6. \\
\hline GCC- $>$ CQ & 0.285 & 0.289 & 0.055 & 5.180 & 0.000 & Regression with \\
\hline $\mathrm{CQ}->\mathrm{GC}$ & 0.188 & 0.192 & 0.067 & 2.830 & 0.005 & moderating variable \\
\hline
\end{tabular}

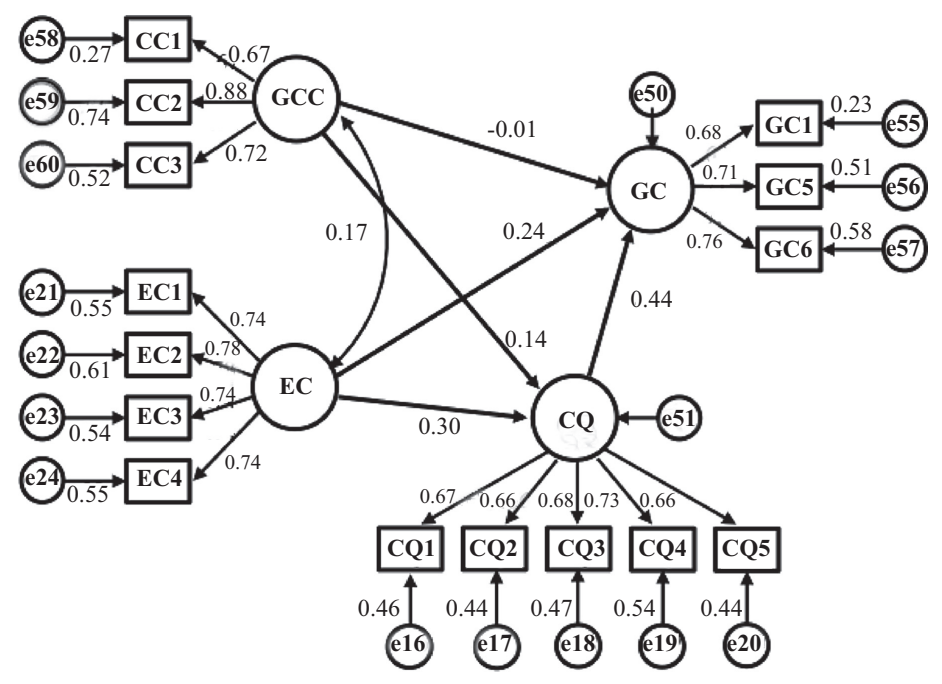

Figure 1. Estimated structural equation model moderating variable 
Figure 1 shows that among the three constructs, CQ has the most substantial effect on GC (0.44), followed by EC and GCC. Therefore, it is advisable for any efforts to promote sustainable development to focus on CQ that positively influences GC. Figure 1 also indicates that some items with indicators weights that need to be taken into account. For GCC, CC2 that shows that "lifestyle is almost the same as the people of my social class in other countries" has the highest coefficient of 0.88 . "I purchase products manufactured in Indonesia instead of letting other countries get rich off us" EC2 (0.78) is the highest coefficient for EC. GC6 indicates that "helping others no matters what country they are from" becomes an essential element of GC. Hence, the CQ has an item of "change non-verbal behaviour when a cross-cultural interaction" (CQ4) is the most influential element with a coefficient of 0.73 .

\section{Discussion}

\subsection{Theoretical implication}

This study examines how people become more GC by adopting both GCC and EC, which deeply process the experience in a way that improves their CQ. The results indicate that people with $\mathrm{EC}$ tend to promote $\mathrm{GC}$ by involving $\mathrm{CQ}$. This study comes to contradictory conclusions from the previous research, which argues that an individual with high EC becomes less CQ (Young et al., 2017). Traditionally, the consumer theory argues that citizenship and consumption have an oppositional relationship in which the citizen denotes a commitment to the national interest. The approach also explains that consumers focus on self-satisfaction (Kuehn, 2015).

The findings indicate that people with EC tend to have high CQ. This study extends the discussion of sustainable development by addressing a complicated global interdependency (Hart, 1997), which come from altruistic and egoistic components of consumer behaviour (Wynveen et al., 2012).The results gain support from the previous study consumers simultaneously identify the products and services with a national identity may have inconsistency on the order of proposed antecedents toward GC (Bartsch et al., 2016). The positive relationship between $\mathrm{EC}$ and $\mathrm{GC}$ confirm the argument that consumers tend to expose the external cultural forces, without leaving the national. The consumers may no longer necessary live their lives by the local values, norms and behavioural expectations of their local culture. The profound transformation of the political economy has changed the social rights of citizens and threatens their status as citizen altogether. EC allows the customers to embrace their own culture but seek to understand the common ground of various values between diverse with building healthy local communities.

Secondly, this study confirms the role of CQ in consumer culture theory by concluding that GCC does not lead to better GC. Still, CQ is what makes the difference. The CQ of individuals on a diverse team determines whether GCC promotes GC. Consumers with high CQ can manage the consumption culture to come up with $\mathrm{GC}$, which prompts $\mathrm{GC}$ awareness, cultural diversity, social justice, and environmental sustainability. The initiative to promote GC involves a trust-based social network, which becomes the primary determinant to firm competitive advantage (Pratono, 2019). The relationship between consumption and citizenship has changed as a consumer society is becoming more complex, while the entanglements of consumers and citizens become less transparent (Lamla, 2017).The consumers may root in global consumerism, which places social antagonists for limited resources and power. The consumers who consider different community as threats may value the CQ to exploit GC.

\subsection{Managerial implication}

First of all, this study highlights that business organisations should pay attention to global cultural terms to grasp how consumers perceive global brands. The confluence between GC 
and GCC encourages multi-national companies to adopt the GC paradigm that promotes global brand portfolios over the local ones. The practices of GC in marketing activities determine the level of global market integration. Consumers with potential ethnocentric could be a targeted market for global marketers, who attempt to transform the contemporary market. Global communication becomes more useful for marketing strategies than the monoethnic targeted message for young people with multicultural identities (Laroche and Teng, 2019).

Supporting education to promote $\mathrm{GC}$ seems to be a good idea to multinational corporations to understand how consumers perceive a global brand. While GC is becoming more homogeneous, as a result of the increasingly globalised market, supporting social activities is essential to promote brand credibility and equity (Pratono and Tjahjono, 2017) and call for a further business ethics standard. Maintaining a high level of CQ can help the initiative to promote global consumer ethics. Hence, the initiative needs to consider the contradictions between EC and GC. The findings indicate that there is an opportunity to promote GC for those who have high EC.

For the international organisation, the initiative to promote GC should become not only an additional subject for the classroom but also a framework for long life learning to the broader community. This study believes that global civic education will be able to create a foundation for sustainable development. Encouraging young people to become aware of GCC and EC can motivate them to develop the knowledge, skills and values to go partnership with other people in the global movement. A classroom project should concern to nurture the students in the class by encouraging young people to explore their values and to respect the values and opinions of others.

\subsection{Research limitation and future research direction}

First of all, this study used an online survey, which provides an opportunity to reach everyone in the targeted population. Future researches are encouraged to enrich the data analysis with larger coverage sample area and cross-country coverage area by utilising the online survey approach with various languages. The online survey can help increase the response rates (Fan and Yan, 2010), but it is essential to consider that the online survey yields a non-random sample on account of diverse participants. As the study invites anyone relevant, the results cannot ensure the random sample from the targeted population.

Second, individual consumer behaviour may lead to GC, but local political campaigns may prevent these outcomes from happening. This study concerns citizen behaviour but not yet involves the policy context. Hence, the relationship between GC and GCC seems to be complicated. Once the observed respondents may agree with consumer protectionism but thoroughly disagrees with protectionism policy. Consumers may support GC but against the import protection policy, which implies the price of products or services (Feurer et al., 2016). Hence, future studies should solve the puzzle where the GC could become an antecedent of other variables in the SEM model.Various approaches should explore the interactions between GCC and GC in any particular policy to explore the potential contradictions and problems that might emerge.

Finally, the concept of citizenship seems to be different from place to place. A country with many migrant workers may have a different concept from those who live in a remote area. This study used an online survey with Indonesia context, which represents developing countries. The conceptualisation of GC needs to broaden to cover various elements, including specific products and services. Hence, the initiative to make the findings be a basis for generalisation needs to be careful. Similar research may have different results if we conduct in different places with different level of the developing economy. Future studies should broaden the sample for data collection to include more than one nation to explore different contexts and a different time with specific products and policy.
Mediating effect of cultural intelligence

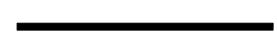




\section{Conclusion}

This study extends the discussion on achieving sustainable development by questioning the conventional wisdom of globalisation, which states that international trade helps countries to enhance their income-generating capacity (United Nations, 2015). The combination of sustainable development and consumer culture theory leads to a better understanding of GC, which demonstrates the institutional conditions. The results do not only extend the concept of sustainable development goals but also the theory of consumer culture by testing some possible points of intervention in applied work. The mediating effect of CQ reveals possible causal mechanisms between GCC and GC.

\section{References}

Andresen, M. and Bergdolt, F. (2017), "A systematic literature review on the definitions of global mindset and cultural intelligence - merging two different research streams", International Journal of Human Resource Management, Vol. 28 No. 1, pp. 170-195.

Ang, S. and Van Dyne, L. (2015), "Handbook of Cultural Intelligence, Routledge, London.

Annear, M.J. (2018), "Knowledge of dementia among the Australian Health Workforce: a national online survey", Journal of Applied Gerontology, Vol. 39 No. 1, pp. 62-73.

Arnould, E.J. (2010), "Society, culture, and global consumer culture" in Cook, D.T. and Ryan, J.M. (Eds), The Wiley Blackwell Encyclopedia of Consumption and Consumer Studies, John Wiley \& Sons, Ltd., Chicester.

Arnould, E.J. and Thompson, C.J. (2005), "Consumer culture theory (CCT): twenty years of research", Journal of Consumer Research, Vol. 31 No. 4, pp. 868-882.

Balabanis, G. and Siamgka, N.-T. (2017), "Inconsistencies in the behavioural effects of consumer ethnocentrism: the role of brand, product category and country of origin", International Marketing Review, Vol. 34 No. 2, pp. 166-182.

Banna, A.E., Papadopoulus, N., Murphy, S.A., Rod, M. and Rojas-Méndez, J. (2018), "Ethnic identity, consumer ethnocentrism, and purchase intentions among bicultural ethnic consumers: 'Divided loyalties' or 'dual allegiance'?”, Journal of Business Research, Vol. 82, pp. 310-319.

Barbarossa, C., Del Pelsmacker, P. and Moons, I. (2018), "Effects of country-of-origin stereotypes on consumer responses to product-harm crises", International Marketing Review, Vol. 35 No. 3, pp. 362-389.

Barnes, J. (2015), "Women leading through the lens of cultural intelligence", in Ngujiri, F.W. and Madsen, S.R. (Eds), Women as Global Leaders, pp. 95-118, Information Age Publishing, Charlotte.

Baron, R.M. and Kenny, D.A. (1986), "Moderator-mediator variable distinction in social psychological research: conceptual, strategic, and statistical considerations", Journal of Personality and Social Psychology, Vol. 51 No. 6, pp. 1173-1183.

Bartsch, F., Diamantopoulos, A., Paparoidamis, N.G. and Chumpitaz, R. (2016), "Global brand ownership: the mediating roles of consumer attitudes and brand identification", Journal of Business Research, Vol. 69, pp. 3629-3635.

Bartsch, F., Piefler, P. and Diamantopoulos, A. (2016), "A taxonomy and review of positive consumer dispositions toward foreign countries and globalization”, Journal of International Marketing, Vol. 24 No. 1, pp. 82-110.

Baruk, A.I. (2019), “The effect of consumers' ethnocentric attitudes on their willingness for presumption", Heliyon, Vol. 5, pp. 1-9.

Bernardo, A.B. and Presbitero, A. (2017), "Belief in polyculturalism and cultural intelligence: individual- and country-level differences", Personality and Individual Differences, Vol. 119, pp. 307-310. 
Boutilier, R. (2017), Stakeholder Politics: Social Capital, Sustainable Development, and the Corporation, Routledge, London.

Brannen, J. (2016), “Combining qualitative and quantitative approaches: an overview”, Mixing Methods: Qualitative and Quantitative Research, Routledge, New York, pp. 3-38.

Brown, G. (2016), The Universal Declaration of Human Rights in the 21st Century: A Living Document in a Changing World, Open Book Publisher, Cambridge.

Buket, A. and Oktay, D. (2018), "Exploring environmental behaviour as the major determinant of ecological citizenship", Sustainable City and Society, Vol. 39, pp. 765-771.

Burgoon, J.K., Guerrero, L.K. and Floyd, K. (2016), Nonverbal Communication, Routledge, London.

Carter, A. (2013), The Political Theory of Global Citizenship, Routledge, London.

Casado-Aranda, L.-A., Sánchez-Fernández, J. and Ibánez-Zapata, J.-Á. (2020), “reserved.How consumer ethnocentrism modulates neural processing of domestic and foreign products: a neuroimaging study", Journal of Retailing and Consumer Services, Vol. 53, pp. 1-9.

Cleveland, M., Rojas-Méndez, J., Laroche, M. and Papadopoulos, N. (2016), "Identity, culture, dispositions and behavior: a cross-national examination of globalization and culture change", Journal of Business Research, Vol. 69, pp. 1090-1102.

Cook, D.T. and Ryan, J.M. (2015), The Wiley Blackwell Encyclopedia of Consumption and Consumer Studies, John Wiley \& Sons, New York.

Cushner, K. (2015), "Development and assessment of intercultural competence", in Hayden, M., Levy and Thomson, J. (Eds), The Sage Handbook of Research in International Education, Sage, Los Angeles, pp. 200-216.

Dey, B.L., Yen, D. and Samuel, L. (2020), "Digital consumer culture and digital acculturation", International Journal of Information Management, Vol. 51, pp. 1-6.

Dobson, A. (2007), "Environmental citizenship: toward sustainable development", Sustainable Development, Vol. 15, pp. 276-285.

Earley, P.C., Ang, S. and Tan, J.-S. (2006), CQ: Developing Cultural Intelligence at Work, Stanford University Press, Stanford.

Fan, W. and Yan, Z. (2010), "Factors affecting response rates of the web survey: a systematic review", Computers in Human Behavior, Vol. 26, pp. 132-139.

Feurer, S., Baumbach, E. and Woodside, A.G. (2016), "Applying configurational theory to build a typology of ethnocentric consumers”, International Marketing Review, Vol. 33 No. 3, pp. 351-375.

Giorgi, S., Bartunek, J.M. and King, B.G. (2017), "A Saul Alinsky primer for the 21st century: the roles of cultural competence and cultural brokerage in fostering mobilization in support of change", Research in Organizational Behavior, Vol. 37, pp. 125-142.

Goh, M. (2012), "Teaching with cultural intelligence: developing multiculturally educated and globally engaged citizens", Asia Pacific Journal of Education, Vol. 32 No. 4, pp. 395-415.

Goodier, S., Field, C. and Goodman, S. (2018), "The need for theory evaluation in global citizenship programmes: the case of the GCSA programme", Evaluation and Program Planning, Vol. 66, pp. 7-19.

Goodman, D.J. and Cohen, M. (2004), Consumer Culture: A Reference Handbook, ABC-CLIO, Santa Barbara, California.

Hahn, R. (2009), "The ethical rational of business for the poor - integrating the concepts of bottom of the pyramid, sustainable development, and corporate citizenship", Journal of Business Ethics, Vol. 84, pp. 313-324.

Han, C.M. and Guo, C. (2018), "How consumer ethnocentrism (CET), ethnocentric marketing, and consumer individualism affect ethnocentric behavior in China”, Journal of Global Marketing, Vol. 31. No. 5, pp. 324-338. 
Hart, S. (1997), "From global citizenship to sustainable development", in Tichy, N.M., McGill, A.R. and Clair, L.S. (Eds), Corporate Global Citizenship: Doing Business in the Public Eye, The New Lexington Press, San Francisco, pp. 249-259.

$\mathrm{Hu}, \mathrm{S}$., Liu, H. and Gu, J. (2018), "What role does self-efficacy play in developing cultural intelligence from social media usage?”, Electronic Commerce Research and Applications, Vol. 28, pp. 172-180.

Huff, K.C., Song, P. and Gresch, E.B. (2014), "Cultural intelligence, personality, a cross-cultural adjustment: a study of expatriates in Japan", International Journal of Intercultural Relations, Vol. 38, pp. 151-157.

Ismail, M. and Nisar, T. (2015), "Conceptualizing knowledge transfer between expatriates and host country nationals: the mediating effect of social capital", Congen Business and Management, Vol. 2 No. 1, doi: 10.1080/23311975.2015.1101803.

Kim, H. and Qu, H. (2020), “The mediating roles of gratitude and obligation to link employees' social exchange relationships and prosocial behavior", International Journal of Contemporary Hospitality Management, Vol. 32 No. 2, pp. 644-664.

Klein, J.G. and Ettensoe, R. (1999), "Consumer animosity and consumer ethnocentrism: an analysis ofunique antecedents", Journal of International Consumer Marketing, Vol. 11 No. 4, pp. 5-24.

Knapp, M.L., Hall, J.A. and Horgan, T.G. (2014), Nonverbal Communication in Human Interaction, Wadsworth, Boston, US.

Korzilius, H., Bücker, J.J. and Beerlage, S. (2017), "Multiculturalism and innovative work behavior: the mediating role of cultural intelligence", International Journal of Intercultural Relations, Vol. 56, pp. 13-24.

Kuehn, K. (2015), “Citizenship and Consumption”, in Cook, D.T. and Ryan, J.M. (Eds), The Wiley Blackwell Encyclopedia and Consumer Studies, John Wiley \& Sons, Ltd., Chicester.

Lamla, J. (2017), "The social bond of consumer citizen: exploring consumer democracy with actornetwork-pragmatism", in Mackert, J. and Turner, B.S., The Transformation of Citizenship, Routledge, London, pp. 137-151.

Laroche, M. and Teng, L. (2019), "Understanding the global consumer culture: views from eastern and western T scholars, an introduction to the special issue", Journal of Business Research, Vol. 103, pp. 219-221.

Laroche, M. (2016), "Advancing knowledge of the global consumer culture: introduction to the special issue", Journal of Business Research, Vol. 69, pp. 1071-1073.

Lehmberg, D., Dhanaraj, C. and Funai, A. (2013), "What do we make of Japan? Myths and realities", Business Horizons, Vol. 56 No. 2, pp. 219-229.

Lekakis, E.J. (2015), "Economic nationalism and the cultural politics of consumption under austerity: the rise of ethnocentric consumption in Greece", Journal of Consumer Culture, Vol. 17 No. 2, pp. 286-302.

Lianaki-Dedouli, I. and Plouin, J. (2017), "Bridging anticipation skills and intercultural competencies as a means to reinforce the capacity of global citizens for learning to learn together", Futures, Vol. 94, pp. 45-58.

Lyons, K., Hanley, J., Wearing, S. and Neil, J. (2012), "Gap year volunteer tourism: myths of global citizenship?”, Annals of Tourism Research, Vol. 39 No. 1, pp. 361-378.

Martin, P. and Beteson, P. (2004), "Measuring Behaviour: An Introductory Guide, Cambridge University Press, Cambridge.

McCrindle, A. (2010), "In search of high CQ: a trendy management idea for the age of globalization", The Economist, available at https:/www.economist.com/business/2010/04/06/in-search-of-highcq (accessed 19 April 2020).

Mekpor, B. and Dartey-Baah, K. (2020), "Beyond the job description: exploring the mediating role of leaders' emotional intelligence on the nexus between leadership styles and voluntary workplace 
behaviours in the Ghanaian banking sector", Journal of Management Development, Vol. 39 No. 2, pp. 240-252, available at: doi: 10.1108/JMD-04-2019-0104.

Okazaki, S., Mueller, B. and Taylor, C.R. (2010), "Global consumer culture positioning: testing perceptions of soft-sell and hard-sell advertising appeals between U.S. and Japanese consumers", Journal of International Marketing, Vol. 18 No. 2, pp. 20-34.

Pekerti, A.A. and Arli, D. (2017), "Do cultural and generational cohort matter to ideologies and consumer ethics? A comparative study of Australian, Indonesia, and Indonesian migrants in Australia”, Journal of Business Ethics, Vol. 143 No. 2, pp. 387-404.

Pratono, A.H. and Maharani, A. (2018), "Long-term care in Indonesia: the role of integrated service post for elderly", Journal of Aging and Health, Vol. 30 No. 10, pp. 1556-1573.

Pratono, A.H. and Tjahjono, G. (2017), "How does materialistic attitude influence the impact of corporate brand on the customers' intention to donate to corporates' charity?", Humanomics, Vol. 33 No. 4, pp. 484-498.

Pratono, A.H. (2019), "Cross-cultural collaboration for inclusive global value chain: a case study of rattan industry", International Journal of Emerging Markets, Vol. 15 No. 1, pp. 149-170.

Presbitero, A. and Toledano, L.S. (2017), "Global team members' performance and the roles of crosscultural training, cultural intelligence, and contact intensity: the case of global teams in IT offshoring sector", International Journal of Human Resource Management, Vol. 29 No. 14, pp. 2188-2208.

Reysen, S. and Hackett, J. (2017), "Activism as a pathway to global citizenship”, The Social Science Journal, Vol. 54, pp. 132-138.

Scott, M.L. and Cnaan, R.A. (2020), "Youth and religion in an age of global citizenship identification: an 18- country study of youth", Children and Youth Services Review, Vol. 110, pp. 1-9.

Sharma, N. and Hussain, D. (2017), "Current status and future directions for cultural intelligence", Journal of Intercultural Communication Research, Vol. 46 No. 1, pp. 96-110.

Sharma, S., Shimp, T.A. and Shin, J. (1995), "Consumer ethnocentrism: a test of antecedents and moderators", Journal of the Academy of Marketing Science, Vol. 23 No. 1, pp. 26-37.

Sheth, J. and Maholtra, N. (2009), Encyclopedia of International Marketing, Wiley, London.

Shrout, P.E. and Bolger, N. (2002), "Mediation in experimental and nonexperimental studies: new procedures and recommendations", Psychological Methods, Vol. 7, pp. 422-445.

Siagmaka, N.-T. and Balabanis, G. (2015), "Revisiting consumer ethnocentrism: review, reconceptualization, and empirical testing", Journal of International Marketing, Vol. 23 No. 3, pp. 66-86.

Smith, M.B., Laurie, N., Hopkins, P. and Olson, E. (2013), "International volunteering, faith and subjectivity: negotiating cosmopolitanism, citizenship and development", Geoforum, Vol. 45, pp. 126-135.

Stizhakova, Y., Coulter, R.A. and Price, L.L. (2008), "Branded products as a passport to global citizenship: perspectives from developed and developing countries", Journal of International Marketing, Vol. 16 No. 4, pp. 57-85.

Trede, F., Bowles, W. and Bridges, D. (2013), "Developing intercultural competence and global citizenship through international experiences: academics' perceptions", Intercultural Education, Vol. 24 No. 5 , pp. $442-455$.

Tseng, T.-H., Balabanis, G. and Liu, M.T. (2018), "Explaining inconsistencies in implicit and explicit attitudes towards domestic and foreign products", International Marketing Review, Vol. 35 No. 1, pp. 72-92.

UNESCO (2015), Education 2030 Agenda and Framework for Action, available at: http://uis.unesco.org/ sites/default/files/documents/education-2030-incheon-framework-for-action-implementation-of-sd g4-2016-en_2.pdf (accessed 18 April 2020).
Mediating effect of cultural intelligence 
United Nations (2015), Transforming our World: The 2030 Agenda for Sustainable Development, available at: https://sustainabledevelopment.un.org/content/documents/21252030\%20Agenda \% 20for \%20Sustainable\%20Development\%20web.pdf (accessed 12 April 2020).

United Nations (2015), Transforming Our World: The 2030 Agenda for Sustainable Development, Division for Sustainable Development Goals Department of Economic and Social Affairs, New York.

Upvall, M.J. and Luzincourt, G. (2019), "Global citizens, healthy communities: integrating the sustainable development goals into the nursing curriculum", Nursing Outlook, Vol. 67 No. 6, pp. 649-657.

Wang, C.L. (2004), "Consumer ethnocentrism and willingness to buy domestic products in a developing country setting: testing moderating effects", Journal of Consumer Marketing, Vol. 21 No. 6, pp. 391-400.

Wynveen, C.J., Kyle, G.T. and Tarrant, M.A. (2012), "Study abroad experiences and global citizenship: fostering proenvironmental behavior", Journal of Studies in International Education, Vol. 16 No. 4, pp. 334-352.

Young, C.A., Haffejee, B. and Corsun, D.L. (2017), "The relationship between ethnocentrism and cultural intelligence", International Journal of Intercultural Relations, Vol. 58, pp. 31-41.

Zeugner-Roth, K.P., Zabkar, V. and Diamantopoulos, A. (2015), "Consumer ethnocentrism, national identity, and consumer cosmopolitanism as driver of consumer behavior: a social identity theory perspective”, Journal of International Marketing, Vol. 23 No. 2, pp. 25-54.

\section{Further reading}

Bajde, D. (2014), "Consumer culture theory: ideology, mythology and meaning in technology consumption", International Journal of Actor-Network Theory and Technological Innovation, Vol. 6 No. 2, pp. 10-25.

Beugelsdijk, S., Kostova, T. and Kunst, V.E. (2017), "Cultural distance and firm internalization: a metaanalytical review and theoretical implications", Journal of Management, Vol. 44 No. 1, pp. 89-130.

Jang, S.M. (2013), "Framing responsibility in climate change discourse: ethnocentric attribution bias, perceived causes, and policy attitudes", Journal of Environmental Psychology, Vol. 36, pp. 27-36.

Kivelä, S. (2018), "Active citizenship, public sector and the markets: freedom of choice as a state project in health care", Geoforum, Vol. 91, pp. 160-169.

Trentmann, F. (2007), “Citizenship and consumption”, Journal of Consumer Culture, Vol. 7 No. 2, pp. 147-158.

Van Dyne, L., Ang, S. and Koh, C. (2015). Development and validation of the CQS”, in Ang, S. and Van Dyne, L. (Eds), Handbook of Cultural Intelligence, Routledge, London, pp. 16-40. 
Annex 1

\section{Mediating effect of cultural intelligence}

Global consumer culture (Cleveland et al, 2016)

CC04 I identify with famous international brands

CC05 I pay attention to the famous worn by people in my age group that live in other countries

CC07 I believe that advertising by foreign or global brands has a strong influence on my clothing choices

Global citizenship (Reysen and Hackett, 2017)

GC1 I understand how the various cultures of this world interact socially

GC2 I am aware that my actions in my local environment may affect people in other countries

GC3 I try to stay informed of current issues that impact international relations

GC4 I believe that I am connected to people in other countries

CQ-behaviour (Ang and Van Dyne, 2015)

CQ1 I change my verbal behaviour (e.g., accent, tone) when a cross-cultural interaction requires it

CQ2 I use pause and silence differently to suit different cross-cultural situations

CQ3 I vary the rate of my speaking when a cross-cultural situation requires it

CQ4 I change my non-verbal behaviour when a cross-cultural interaction requires it

CQ5 I alter my facial expressions when a cross-cultural interaction requires it

Ethnocentric consumerism (Klein, 2002)

EC01 I believe that Indonesian people should always buy Indonesian-made products instead of imports

EC08 I should purchase products manufactured in Indonesia instead of letting other countries get rich off us

EC10 I believe that there should be very little trading or purchasing of goods from other countries unless out of necessity

EC11 I believe that Indonesians should not buy foreign products, because this hurts Indonesian business and causes unemployment

EC14 I believe that foreigners should not be allowed to put their products on our markets

EC15 I believe that foreign products should be taxed heavily to reduce their entry into Indonesia

EC16 I should buy from foreign countries only those products that we cannot obtain within our own country

EC17 I believe that Indonesian consumers who purchase products made in other countries are responsible for putting their fellow Indonesians out of work

Table A1.

The measures

\section{Corresponding author}

Aluisius Hery Pratono can be contacted at: hery_pra@staff.ubaya.ac.id

For instructions on how to order reprints of this article, please visit our website:

www.emeraldgrouppublishing.com/licensing/reprints.htm

Or contact us for further details: permissions@emeraldinsight.com 